\title{
A rare case of sirenomelia with total bilateral cleft lip palate and kyphoscoliosis
}

\author{
Sangeeta Arya*, Anil Kumar Verma, Kiran Pandey, Sunil Kumar Verma
}

Department of Obstetrics \& Gynecology, GSVM Medical College, Kanpur- 208002, U.P., India

Received: 2 April 2013

Revised: 3 April 2013

Accepted: 14 April 2013

\section{*Correspondence:}

Dr. Sangeeta Arya,

E-mail: sangeetanilverma@rediffmail.com

(C) 2013 Arya S et al. This is an open-access article distributed under the terms of the Creative Commons Attribution License, which permits unrestricted use, distribution, and reproduction in any medium, provided the original work is properly cited.

\begin{abstract}
Sirenomelia, a rare congenital deformity, has fused lower limbs with variable combination of visceral anomalies. This condition is fatal within a day or two of birth so early antenatal detection and pregnancy termination is advocated. Antenatally it can be diagnosed by ultrasonography showing oligohydramnios, renal agenesis and fibulae positioned between the tibiae. A 24 years old Muslim primigravida came for first antenatal check up at 18 weeks of pregnancy. She didn't turn up and came directly in emergency at 37 weeks in active labor and delivered a baby weighing $1.8 \mathrm{~kg}$ with a small sized placenta, complete bilateral cleft lip palate, Kyphoscoliosis and fused lower limbs upto ankles. Baby expired after 25 minutes of birth. Till now around 300 cases of Sirenomelia have been reported worldwide. All human cases of Sirenomelia have been found to be associated with variable degree of renal and urethral dysplasia or renal agenesis. External genitalia are affected, whereas gonads remain unaffected. In rare cases Sirenomelia is associated with upper body defects including cleft palate, cervical and upper thoracic vertebral abnormalities, pulmonary hypoplasia and cardiac defects.
\end{abstract}

Keywords: Sirenomelia, Caudal dysgenesis, Cleft-lip-palate, kyphoscoliosis

\section{INTRODUCTION}

Sirenomelia is also known as mermaid syndrome which is a very rare congenital deformity having fused lower limbs giving the appearance of a mermaid's tail along with variable combination of visceral anomalies. The word Sirenomelia has been derived from sirens in Greek mythology that were creatures with the head of a woman and the body of a bird, which later on were portrayed as aquatic creatures resembling mermaid. This is found in 1.1-4.2 per 100,000 live births. ${ }^{1}$ This condition is fatal within a day or two of birth so early antenatal detection is important to allow prenatal counseling for the possible pregnancy termination. Only a few exceptional cases have survived who had functional kidneys. Antenatally it can be diagnosed by ultrasonography showing oligohydramnios, renal agenesis and a fibula positioned between the tibiae. ${ }^{1}$

\section{CASE REPORT}

A 24 years old Muslim primigravida came for first antenatal checkup in August 2008 following 18 weeks of pregnancy. There was no history of fever, X-ray irradiation or any drug intake in first trimester. She had history of chronic tobacco chewing for past 5 years (5-6 pouches in a day). Her past medical and family history was unremarkable and her general and systemic examination was within normal limits and fundal height corresponded with 18 weeks. She was advised routine investigations along with ultrasound for fetal well being and to rule out any congenital anomaly. She was given Iron and calcium supplements and was advised to come 
with investigations in next follow up. She didn't come for further follow up and came in emergency at 37 weeks in active labor. Her general and systemic examination was within normal limits. Per abdominal examination showed fundal height -28 weeks with uterus full of fetus clinically showing grossly reduced liquor in cephalic presentation with FHR 136/min, regular. She delivered a baby weighing $1.8 \mathrm{~kg}$ with a small sized placenta. The baby had complete bilateral cleft lip palate with kyphoscoliosis with fused lower limbs upto ankles.

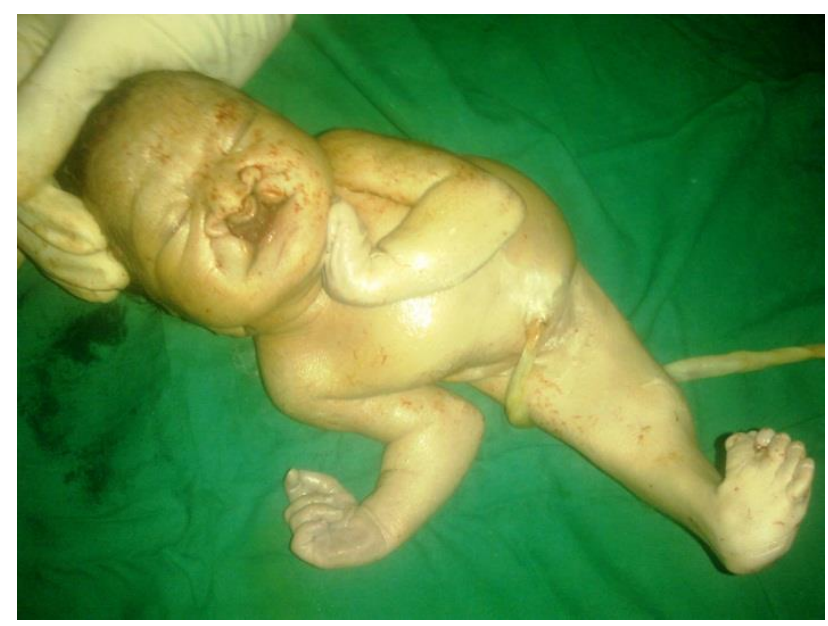

Figure 1: Baby showing fused lower limbs upto ankle.

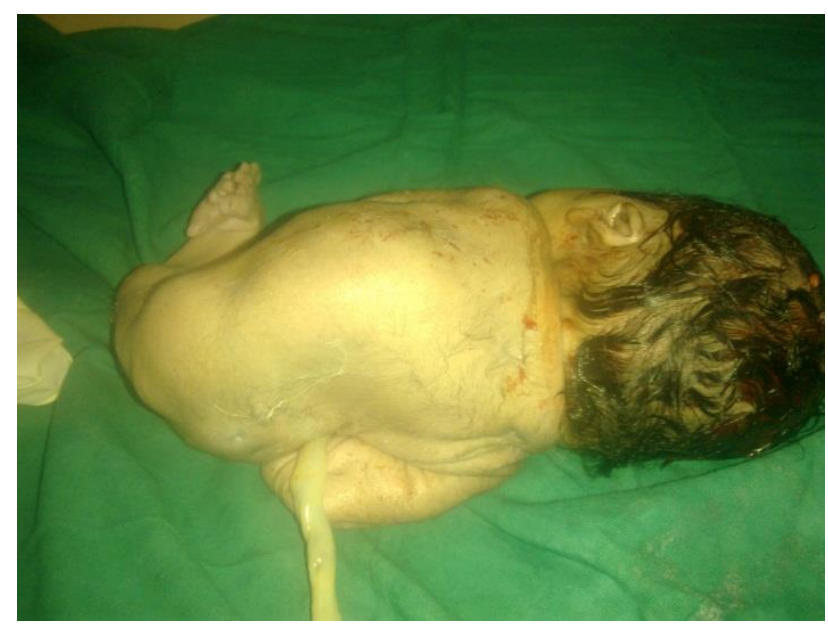

Figure 2: Baby showing Kyphoscoliosis.

Both feet were fused. External genitalia and anal opening could not be identified due to fused lower limbs. Umbilical cord showed single umbilical artery. At birth APGAR score was $5 / 10$ at first minute of birth and $2 / 10$ at fifth minute of birth .Baby expired after 25 minutes of birth. Postpartum period was uneventful. Ultrasound of baby showed absent kidneys. Attendants of the woman did not give consent for $\mathrm{x}$ - ray and autopsy of the baby.

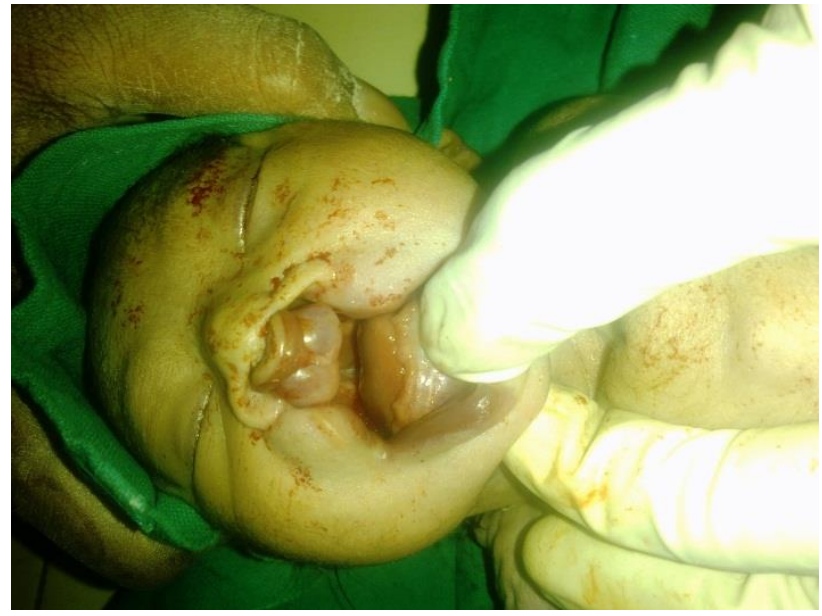

Figure 3: Baby showing bilateral cleft lip and palate.

\section{DISCUSSION}

Till now around 300 cases of sirenomelia have been reported worldwide. Several attempts have been made to classify Sirenomelia. Sirenomelia was called bipus if two feet were present, monopus if one foot and apus if no foot element was discernible. The merged lower limbs in Sirenomelia show an abnormal position that corresponds to an $180^{\circ}$ rotation with respect to the normal position of the leg. During normal limb development the hind limb buds rotate medially so that the ventral surface eventually faces dorsally. Clinical studies of sirenomelia suggest two main pathogenic hypotheses. The first hypothesis which is also called as vascular steal hypothesis is based on the aberrant abdominal and umbilical vascular pattern giving a primary vascular defect that causes the hypoperfusion of the caudal part of the embryo. There is single umbilical artery (SUA) in Sirenomelia invariably. This SUA has abnormal origin from aorta high in abdomen. Below its origin aorta becomes abnormally narrow lacking branches that normally supply kidneys, large intestine and genitalia. ${ }^{2}$ The second hypothesis postulates defective blastogenesis that occurs during the final stages of gastrulation at the tailbud stage corresponding to the third gestational week in humans. ${ }^{2}$

All human cases of sirenomelia have been found to be associated with variable degree of renal and urethral dysplasia but renal agenesis being more frequently noted. External genitalia are either absent or are represented by a tag of tissue, whereas gonads are usually unaffected. The gastrointestinal anomalies include blind ending colon, rectal atresia and imperforate anus. Other anomalies that are found are lumbosacral and pelvic malformations including sacral agenesis, malformed vertebrae and hemivertebrae. In rare cases sirenomelia is associated with upper body defects including cleft palate, cervical and upper thoracic vertebral abnormalities, pulmonary hypoplasia and cardiac defects. ${ }^{2}$ 
Sirenomelia in mice has shown a genetic basis. It occurs in mice lacking Cyp26a1 enzyme which degrades retinoic acid (RA). This is expressed in the caudal region of the embryo and transiently in the developing vascular network. This lack of enzyme results in gain of RA function that leads to several caudal defects. ${ }^{3}$ There still remains need of further research of clinical cases in human beings to know its exact etiology.

Funding: No funding sources

Competing interests: There are no competing interests to declare

Ethical approval: Not required

\section{REFERENCES}

1. Valenzano M, Paoletti R, Rossi A, et al. Sirenomelia: Pathological features, antenatal ultrasonographic clues, and a review of current embryogenic theories. Hum Reprod Update 1999;5:82-6.

2. Martinez-Frias ML, Bermejo E, Rodriguez-Pinilla E, Prieto D. Does single umbilical artery (SUA) predict any type of congenital defect? Clinicalepidemiological analysis of a large consecutive series of malformed infants. Am J Med Genet 2008;146A:15-25.

3. Abu-Abed s, Dolle P, Metzger D, Wood C, Maclean G, Chambon P, Petkovich M. Developing with lethal RA levels: genetic ablation of Rarg can restore the viability of mice lacking Cyp26a1. Development 2003;130:1449-59.

DOI: $10.5455 / 2320-1770 . i j r \operatorname{cog} 20130631$

Cite this article as: Arya S, Verma AK, Pandey K, Verma SK. A rare case of sirenomelia with total bilateral cleft lip palate and kyphoscoliosis. Int $\mathbf{J}$ Reprod Contracept Obstet Gynecol 2013;2:242-4. 